\title{
Bed Separation Characteristics of an LTCC Panel and Subsidence Controlling Grouting: Case Study of Longquan Coal Mine, China
}

\author{
Jun Zheng, ${ }^{1,2}$ Guoqing Zhou, ${ }^{1}$ Yuliang Zhou $\mathbb{D}^{3,}{ }^{3,4}$ Dongfeng Yuan, ${ }^{4}$ and Tielin Zhao ${ }^{3,5}$ \\ ${ }^{1}$ State Key Laboratory for Geomechanics \& Deep Underground Engineering, China University of Mining and Technology, \\ Xuzhou 221116, China \\ ${ }^{2}$ China Coal Guanghua Geology and Engineering Co., Ltd., Handan 056004, China \\ ${ }^{3}$ School of Mechanics and Civil Engineering, China University of Mining \& Technology-Beijing, Beijing 100083, China \\ ${ }^{4}$ Beijing China Coal Mine Engineering Co., Ltd., Beijing 100013, China \\ ${ }^{5}$ CCTEG Coal Mining Research Institute, Beijing 100013, China
}

Correspondence should be addressed to Yuliang Zhou; zhouylscbj@sina.com

Received 12 November 2021; Accepted 12 January 2022; Published 3 February 2022

Academic Editor: Yanbo Zhang

Copyright (c) 2022 Jun Zheng et al. This is an open access article distributed under the Creative Commons Attribution License, which permits unrestricted use, distribution, and reproduction in any medium, provided the original work is properly cited.

The bed separation backfill grouting (BSBG) is commonly used to mitigate the surface subsidence caused by coal mining. The distribution characteristics of bed separation and its dynamic evolving process are crucial for BSBG design. This paper utilizes the continuum-discontinuum element method (CDEM) to study the distribution characteristics of bed separation for a longwall top coal caving (LTCC) panel of Longquan coal mine. Numerical results indicate that in addition to the bed separation below the primary key stratum, several small bed separations may also occurred in the strata between the primary key stratum and the subordinate key stratum. The bed separations in the overburden could be classified into three classes: the upper bed separation, the middle bed separation, and the lower bed separation. The upper bed separation has the longest duration time, and the middle bed separation has the shortest duration time. And the BSBG should be started before the closure of the middle bed separation. Based on the actual geological information, the BSBG scheme for 4203 LTCC panel is proposed to mitigate the surface subsidence by taken the results of numerical simulation into consideration. In addition, the case study of the BSBG is introduced in detail. By using gangue power slurry, BSBG could not only effectively mitigate the surface subsidence but also solve the problems of environmental pollution and land occupation caused by traditional gangue stacking. The present study could provide technical support for surface subsidence mitigation and coal gangue disposal for LTCC mining with similar conditions.

\section{Introduction}

Surface subsidence caused by underground mining is a common environmental problem faced by mining industry worldwide [1-3]. For underground coal mining, especially the thick coal seam extraction by LTCC method, the drastic deformation and caving of the overlying strata could lead to a large-scale ground subsidence $[2,4,5]$. Massive landslides and ground sinkholes, shown in Figure 1, are frequently occurred in the coal mining areas [6]. Excessive land subsidence not only causes damage to the ground buildings and infrastructures $[1,7]$ but also leads to severe environment problems or geological disasters, which seriously threatens the safety of the local inhabitants [2]. Therefore, developing effective controlling technologies for mitigating the mininginduced surface subsidence has been the endeavor of researchers over the past centuries.

At present, the commonly used surface subsidence mitigation techniques in coal mining include pillar and strip mining (PSM), underground goaf backfilling (UGB), and bed separation backfill grouting (BSBG) $[2,5,8-11]$. For a long time, in order to extract the coal seam under the buildings, water bodies, and railways, the PSM method is utilized to control the land subsidence by remaining coal pillars to support the roof strata in the goaf $[10,12]$. The PSM method could effectively control the mining subsidence, but due to the low coal recovery rate and production efficiency, it has been gradually phased out. The UGB technique uses 


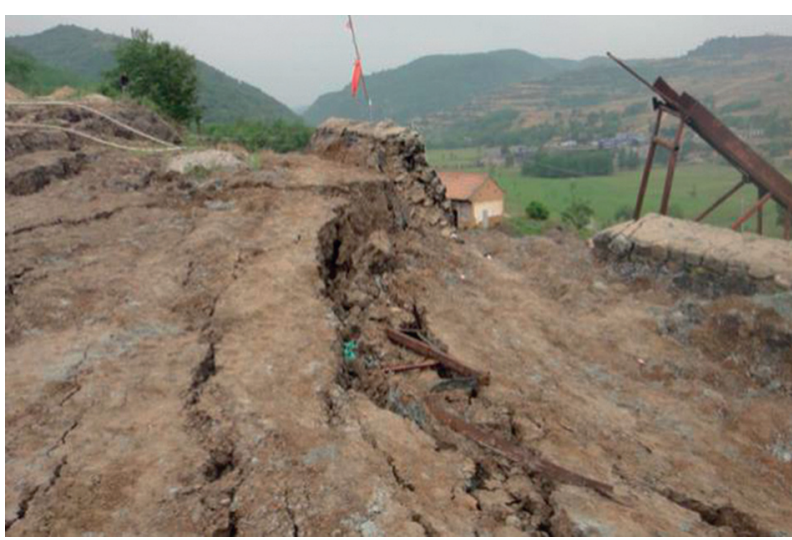

(a)

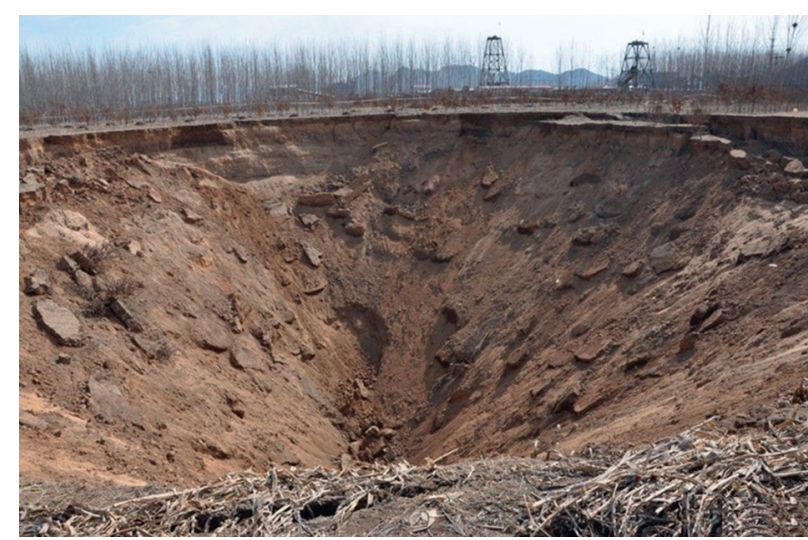

(b)

Figure 1: Photos of typical geological disaster caused by coal mining. (a) Landslides caused by coal mining. (b) Ground sinkhole caused by mining.

gangue, sand, or high water materials to backfill the minedout area for the purpose to form supporting structure in the goaf $[11,13]$. The core idea of UGB method is to construct artificial structures to replace the extracted coal pillar, which means huge amount of backfilling materials and large initial investments and high costs.

In the process of coal seam extraction, the roof strata caving, and filling the gob, generally, the overburden could be divided into "three zones," that is, the caving zone, the fractured zone, and the curved zone [14]. Results of laboratory and field tests indicate that bed separation will occur in the overburden when the bending stiffness of the upper strata is greater than that of the lower strata [15-18]. During the longwall mining, the evolution of bed separation in the overburden is a dynamic process, which can be generally divided into four stages: bed separation motivating, opening, expanding, and closing $[4,19]$. Both laboratory and field tests indicate that the lithology of the overburden, mining depth, working face length, and coal seam thickness are the key factors for the evolution of bed separation $[16,20]$. The technology of BSBG, which utilizes surface grouting to backfill the void space of the bed separation through ground boreholes, is an effective method to mitigate the mininginduced land subsidence. The original idea of BSBG was firstly proposed by scholars in the former Soviet Union [2]. In the late 1980s, the BSBG technology was introduced into China from Poland, and it is successfully applied in Laohuotai Mine of Fushun Coalfield [21]. Subsequently, the SBSG has been widely applied in many coal mines to control the surface subsidence $[2,3,5,20]$. Recently, with the rapid increase of mining intensity and the improvement of environmental requirements, the mining-induced land subsidence has been widely concerned.

Although some efforts have been done to highlight the evolution characteristics of bed separation and rational technical parameters of BSBG in laboratories or field scales, however, most of the literature studies are based on the research of traditional fully mechanized mining face. With the average thickness of coal seam as $6.8 \mathrm{~m}$, Longquan coal mine has a large thickness of coal seam, and the longwall top coal caving (LTCC) method is utilized to extract the thick coal seam. In the LTCC panel, the mined-out area tends to create a larger volume of roof strata subjected to intensive movements and collapse [22]. And the evolution law of bed separation in the overburden is different from that of conventional fully mechanized mining face. Thus, the traditional methods of bed separation estimation can barely satisfy the requirements for subsidence control of the LTCC working face. In addition, the groutability of the overburden is extremely low when the grouting time is earlier than the opening of the bed separation. Furthermore, if the grouting time is later than the closure stage of bed separation, the effect of subsidence mitigation will be poor as the upper strata have subsided. Therefore, the dynamic evolution process of the bed separation is vital important to determine the start time for BSBG. In the present paper, the evolution characteristic of bed separation in overburden of an LTCC panel was studied in detail by utilizing the continuumdiscontinuum element method (CDEM). Then, the BSBG scheme for surface subsidence was introduced based on the results of numerical simulation and field verification. The research results could provide reference for subsidence control in similar conditions.

\section{Basic Theory and Methods}

2.1. BSBG Technique. Bed separation backfill grouting (BSBG) is an effective technology to control ground subsidence in the process of coal mining [3, 5, 20, 23]. Through surface borehole grouting, the BSBG backfills the void space of the bed separation with fly-ash grout or other materials, illustrated in Figure 2. After consolidation, the grout stone starts to support the overburden, mitigates the subsidence to propagate upward, and achieves the purpose of controlling ground subsidence $[2,4,5]$. Generally, the sedimentary coal strata deposit in the layer, the lithology of the coal measure strata varies greatly, and the discontinuous deformation between the strong and weak strata leads to the formation of bed separation in overburden strata. And the bed separation along the weak-strong layer interface plays an important role 


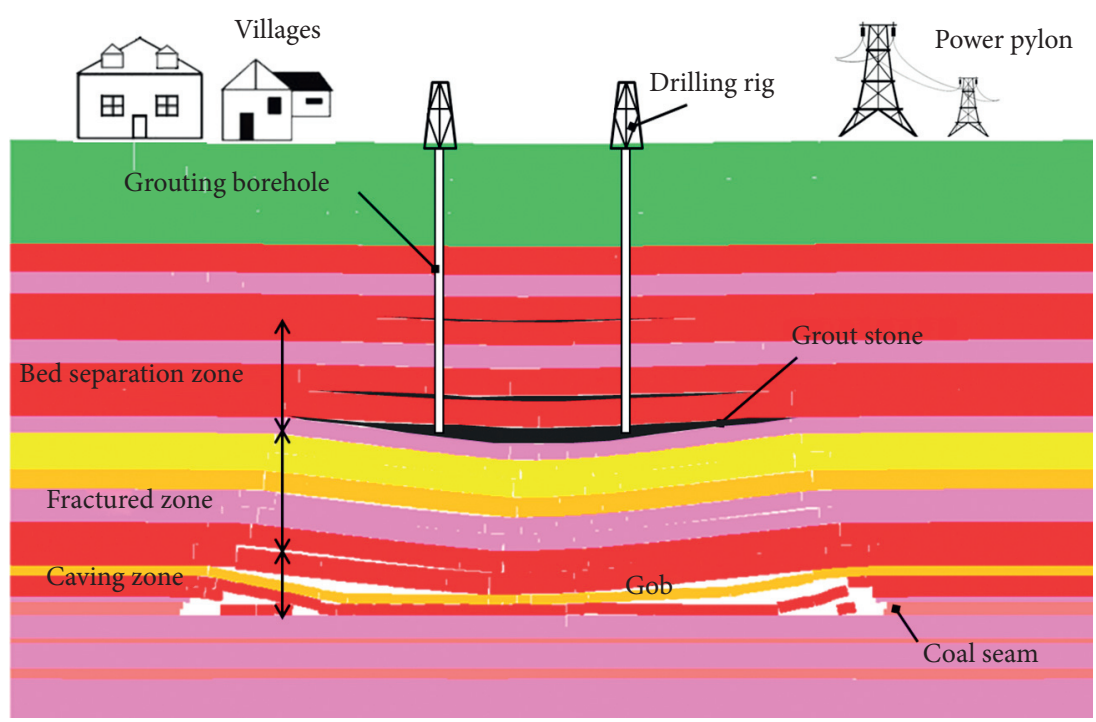

FIgURE 2: Schematic of the BSBG technique to mitigate the surface subsidence.

in the movement and subsidence of the overlying strata [24]. The technique of BSBG aims to eliminate the influence of the bed separation to the surface subsidence by actively backfilling the void space. The cores of BSBG include the prediction of bed-separation position, the volume calculation of bed separation, the dynamic evolution of bed-separation development, and the technical parameters of BSBG [25]. If the BSBG method is blindly used, it could not achieve the desired subsidence controlling results.

Generally, the grouting materials used in the BSBG are fly ash, clay, and natural sand, which indicate a low engineering cost. In addition, the BSBG implemented on the surface ground; it does not interfere with underground coal extraction. Furthermore, by utilizing complete sets of large drilling and grouting equipment, the BSBG has high grouting efficiency and could fully meet the needs of backfill grouting on large scale. The technique of SBSG could not only mitigate ground subsidence effectively but also consume a large amount fly ash, coal gangue, and other industrial wastes, which is conducive to the sustainable development of the green mining for coal mines [26, 27]. Owing to the above advantages, the BSBG has been widely used in the coal industry to mitigate the mining-induced surface subsidence.

\subsection{Technique Parameters for BSBG}

2.2.1. The Borehole Depth of BSBG. It is challenging to accurately predict the location of bed separation in the overburden due to the complexity and uncertainty of the geological lithology. Generally, the bed separation is generated along weak strong rock layers interfaces [15]. According to the key-stratum theory, the bed separation is mainly occurred beneath each key stratum in the overburden, and the maximum height of the void space of the bed separation is directly beneath the primary key stratum. If the primary key stratum is ruptured, the void space of the bed separation will penetrate upward and lead to great surface subsidence [28]. It is crucial to avoid the broken of the primary key stratum for the purpose of ensuring large surface subsidence to not happen. Hence, the borehole depth of BSBG should be greater than that of the floor of the keystratum. Simultaneously, it necessary to avoid the grout flow into the goaf through the water-conductive fracture in the backfilling grouting. Hence, some water-resisting stratum should be designed upon the vertical water-conductive fractures, and the thickness of the water-resisting stratum is $20 \sim 50 \mathrm{~m}$ in general [19]. Therefore, the borehole depth of BSBG can be determined by

$$
H_{w f}<H_{G} \leq H_{k},
$$

where $H_{w f}$ stands for the depth of the vertical water-conductive fractures and $H_{k}$ is the depth of the primary keystratum.

2.2.2. The Rational Grouting Time for BSBG. The movement of the overburden is penetrated from the gob up to the overlying stratum gradually, and the generation of the bed separation is lag behind the underground panel face. In early days, the water pressure test from the surface borehole was utilized to study the initiation of the bed separation beneath the key-stratum. When the pressure fell to zero in the water pressure test, the horizontal distance from the borehole to the panel face is defined as the "lag distance" for bed separation opening [19]. The lag distance is range from 40 to $100 \mathrm{~m}$ generally and is closely related to the thickness of the coal seam, length of the mining panel, lithology of the overburden, and so on. As the bed separation experiences a dynamic evolution process, the bed separation starts to closing when its void space reaches the maximum value. Therefore, the BSBG should be started later than the bed separation's opening time while earlier than the time when bed separation starts to closing. Field tests indicate that the duration from the opening to the closure of the bed separation varies from three to six months, and the upper bed 
separation beneath the primary key-stratum has a longer duration than that of the lower bed separation beneath the subordinate key-stratum. Hence, repeated grouting should be utilized in the bed separation duration.

\subsection{Basic Theory of CDEM}

2.3.1. Fundamental Principles of CDEM. The continuumdiscontinuum element method (CDEM) is a hybrid simulation method, which couples the FEM and the DEM $[29,30]$. CDEM is mainly used to simulate the progressive failure process of geotechnical materials [31-33]. In a CDEM model, illustrated in Figure 3, the computational domain is generated by a series of discrete block which is discretized with a mesh consisting of finite elements [34]. The interface elements, acting as a bond, are embedded between the edges of all adjacent blocks. Actually, the interface elements can be viewed as springs, and its state is judged by the tension-shear composite criterion. For example, if the forces pulling the jointed two blocks apart exceed the ultimate tensile strength, a crack is created by breaking the bond.

2.3.2. Failure Criterion of the Discrete Block. Experimental result shows the shear strength of the material is closely related to the confining pressure [35]. Hence, a combined criterion of maximum tensile stress criterion and Mohr-Coulomb criterion is implemented in the CDEM code.

If the minimum principal stress is smaller than the negative value of tensile strength, the block experiences a tension failure, and the direction of the fracture is orthogonal to the direction of the minimum principal stress.

$$
\sigma_{3} \leq-R_{t}
$$

where $\sigma_{3}$ stands for the minimum principal stress and $R_{t}$ is the tensile strength of the material.

When the shear stress of an oblique section reaches the shear strength, the block will experience a shear failure, and the angle is $(\pi / 4+\phi / 2)$ between the direction of the fracture and the minimum principal stress.

$$
\sigma_{1} \geq 2 c \tan \left(\frac{\pi}{4}+\frac{\phi}{2}\right)+\sigma_{3} \tan ^{2}\left(\frac{\pi}{4}+\frac{\phi}{2}\right),
$$

where $c$ stands for the cohesion and $\phi$ is the fracture friction angle.

\section{Details of the Case Study}

3.1. Engineering Background. Longquan coal mine locates in Loufan County, Taiyuan City, Shanxi Province, shown in Figure 4. The mining area is about $35.23 \mathrm{~km}^{2}$, and the production capacity of this mine is $44 \mathrm{Mt} / \mathrm{a}$. At present, the longwall top coal caving (LTCC) mining method is utilized to extract the $4 \#$ coal seam, which is a thick coal seam. The 4203 panel, which has an inclined width of $250 \mathrm{~m}$ and a strike length of $2200 \mathrm{~m}$, is a large cutting height LTCC panel. The average thickness of the $4 \#$ coal seam is $6.8 \mathrm{~m}$, and the buried depth of the coal seam is range from $473 \mathrm{~m}$ to $548 \mathrm{~m}$. A typical borehole log of roof stratum for the 4203 panel is shown in Figure 5, and the overburden comprises fine- to medium-grained sandstone and mudstone. On the ground, the east side of panel is the Tai-xing Railway, the south side is the village, and the west side is the industrial square. In order to avoiding damages to the villages, railways, and other infrastructures, the BSBG technique is utilized to reducing the coal mining-induced land subsidence.

During the advancement of the working face, the position of bed separation in overburden is not fixed. In order to design the drilling depth and to predict the grouting volume, it is necessary to determine the dynamic evolution law of bed separation with the advance of the LTCC face. In the horizontal direction, the maximum separation position lags behind the working face and moves forward with the working face. In the vertical direction, the separation position is gradually raised, the upper bed separation gradually develops, and the lower bed separation gradually closes. Longquan coal mine has a great mining depth, and there are multilayer subkey stratums under the main key stratum (KS) in overburden. The main KS is located at a high position and far away from the coal seam. Owing to the great mining height, the low KS breaking, and filling the goaf, the evolution law of separation layer is complex.

\subsection{Numerical Simulation of the Bed Separation Distribution}

3.2.1. Set Up of the Numerical Model. For the purpose of obtaining the separation time and the distribution of the void space for the bed separation, the CDEM code was utilized to simulate the dynamic evolution characteristics of overlying bed separation. The CDEM couples the FEM and the DEM, and it is capable to simulate the deformation and failure process of brittle materials from the continuous state to the discontinuous state $[32,36,37]$. In the continuous block, the FEM method is utilized to study the deformation of each element according to the constitutive relation of the rock material while the DEM is adopted on the interface between the continuous blocks. Due to the advantages of capability to simulate the fracture propagation in the failure process, the CDEM has been widely used in various civil and geotechnical engineering [37].

The numerical simulation model (shown in Figure 6), which is $500 \mathrm{~m}$ in length and $240 \mathrm{~m}$ in height, is established according to the actual geological conditions of 4203 panel. The average thickness of the $4 \#$ coal seam is $6.8 \mathrm{~m}$, and the overlying strata are mainly sandstone-mudstone sequence. The physical and mechanical properties of the strata used in the numerical model were listed in Table 1 . The hybrid mesh generation method is adopted, and the block shape adopts mixed polygons, including triangles and quadrilaterals. Compared with the particle model, the block model can better characterize the nonuniform crushing state of roof strata and truly simulate the interaction between the fragments. The boundary conditions are as follows: the horizontal displacement of the left and right boundaries of the model is fixed, the vertical displacement is fixed at the bottom, and the vertical stress, calculated according to the 

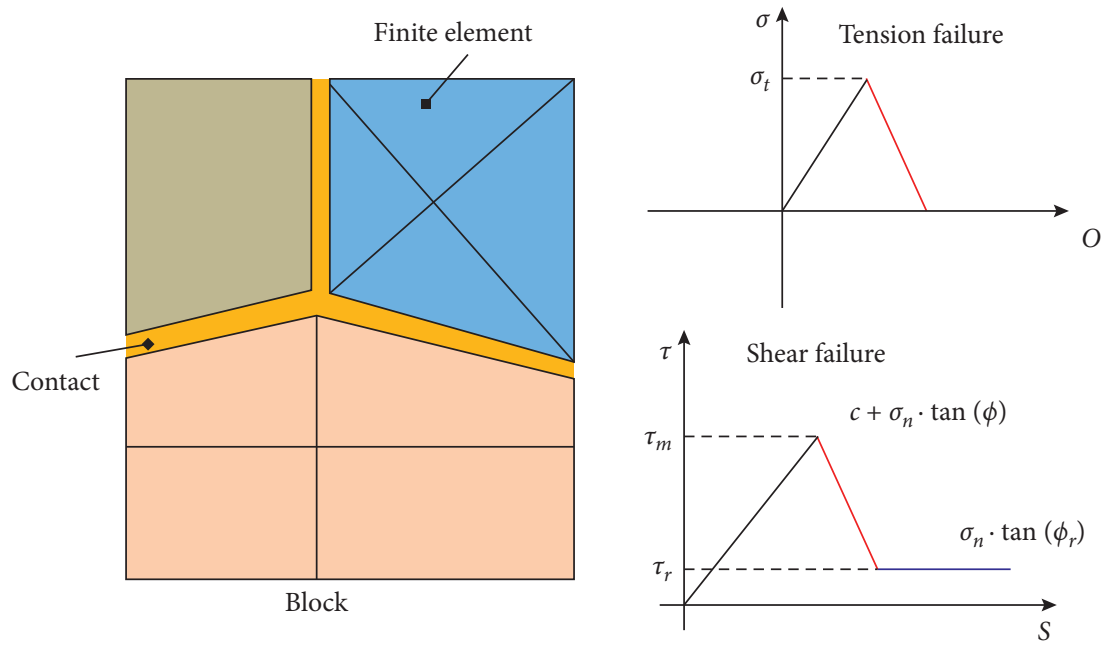

Figure 3: Schematic diagram of CDEM model.

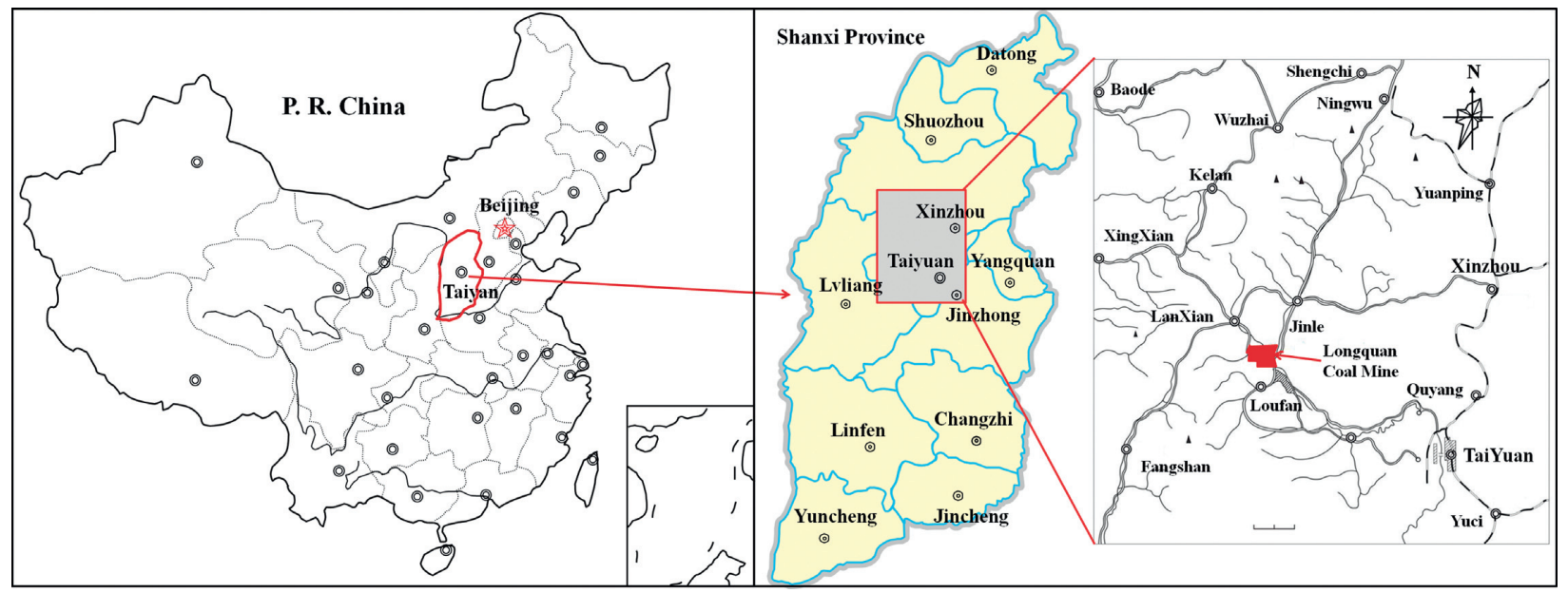

Figure 4: Location of the Longquan coal mine.

buried depth and the overburden density, is applied to the top boundary. During the simulation process, an initial equilibrium is acquired from iteration firstly. Then, the bed separation occurred in the overburden is simulated with the extraction of the $4 \#$ coal seam.

3.2.2. Evolution of the Bed Separation. With the advancing of the LTCC working face, the occurrence of the bed separation in the overburden is a dynamic evolution process. The CDEM simulation results of the evolution characteristics of bed separation of the 4203 LTCC panel are shown in Figure 7. In the CDEM simulation process, the vertical displacement of overburden is monitored, and the maximum separation opening of the lower, middle, and upper bed separation with the advancing distance of the working face can be obtained, shown in Figure 8. When the LTCC face advances $70 \mathrm{~m}$, the rock beam of the main roof breaks, which resulting in initiation of lower bed separation under the lower key stratum (KS). The lower bed separation is $47 \mathrm{~m}$ away from the roof of the $4 \#$ coal seam. The lower bed separation is just distributed upon the vertical fracture zone, and it is rapidly developed with the LTCC face advancing. When the LTCC face advances $120 \mathrm{~m}$, the upper bed separation begins to generate under the upper KS, and the upper bed separation is $160 \mathrm{~m}$ away from the roof of the coal seam. At this condition, the lower bed separation continues to expand. When the LTCC face is advanced $150 \mathrm{~m}$, several small bed separations are generated between the upper and lower KS.

Those small bed separations are caused by the uncoordinated settlement deformation owing to different bending stiffness of the strata. At this point, the lower bed separation reaches its maximum $(3.85 \mathrm{~m})$ and begins to close, shown in Figure 8. The upper bed separation continues to keep expanding. When the LTCC face advances $190 \mathrm{~m}$, the small bed separations in the middle evolve into main bed separations. And in the process, the lower bed separation continues to keep closing while the upper bed separation continues to keep expanding.

When the LTCC face advances $210 \mathrm{~m}$, the middle of the lower bed separation is closed. The upper bed separation and 


\begin{tabular}{|c|c|c|c|c|}
\hline No. & Depth/m & Thincness/m & Columnar & Lithology \\
\hline 1 & 208.00 & 16.90 & & Sandy mudstone \\
\hline 2 & 221.50 & 13.50 & & Mudstone \\
\hline 3 & 226.70 & 5.20 & & Fine sandstone \\
\hline 4 & 229.50 & 2.80 & & Sandy mudstone \\
\hline 5 & 232.40 & 2.90 & & Fine sandstone \\
\hline 6 & 241.00 & 8.60 & & Sandy mudstone \\
\hline 7 & 248.50 & 7.50 & & Siltstone \\
\hline 8 & 265.20 & 16.70 & & Mudstone \\
\hline 9 & 280.90 & 15.70 & & Sandy mudstone \\
\hline 10 & 286.00 & 5.10 & & Siltstone \\
\hline 11 & 289.20 & 3.20 & & Medium sandstone \\
\hline 12 & 298.00 & 8.80 & & Fine sandstone \\
\hline 13 & 312.50 & 14.50 & & Siltstone \\
\hline 14 & 344.80 & 32.30 & & Sandy mudstone \\
\hline 15 & 350.30 & 5.50 & & Fine sandstone \\
\hline 16 & 359.90 & 5.30 & & Sandy mudstone \\
\hline 17 & 364.50 & 4.60 & & Mudstone \\
\hline 18 & 367.00 & 2.50 & & Coarse mudstone \\
\hline 19 & 381.30 & 14.30 & & Sandy mudstone \\
\hline 20 & 382.70 & 1.40 & & Medium sandstone \\
\hline 21 & 397.50 & 14.80 & & Sandy mudstone \\
\hline 22. & 402.30 & 4.80 & & Fine sandstone \\
\hline 23 & 415.80 & 13.50 & & Sandy mudstone \\
\hline 24 & 419.00 & 3.20 & & Siltstone \\
\hline 25 & 431.80 & 12.80 & & Sandy mudstone \\
\hline 26 & 435.00 & 3.20 & & Mudstone \\
\hline 27 & 443.70 & 8.70 & & Sandy mudstone \\
\hline 28 & 448.90 & 5.20 & & Fine sandstone \\
\hline 29 & 462.00 & 13.10 & & Sandy mudstone \\
\hline 30 & 463.50 & 1.50 & & Mudstone \\
\hline 31 & 466.00 & 2.50 & & Siltstone \\
\hline 32 & 482.00 & 16.00 & & Sandy mudstone \\
\hline 33 & 485.00 & 3.00 & & Siltstone \\
\hline 34 & 488.70 & 3.70 & & Mudstone \\
\hline 35 & 492.40 & 3.70 & & Sandy mudstone \\
\hline 36 & 494.50 & 2.10 & & Carbon mudstone \\
\hline 37 & 499.00 & 4.50 & & Mudstone \\
\hline 38 & 506.30 & 7.30 & & Sandy mudstone \\
\hline 39 & 507.30 & 1.00 & & Siltstone \\
\hline 40 & 508.93 & 1.63 & & Sandy mudstone \\
\hline 41 & 515.93 & 7.00 & & Coal \\
\hline 12 & 518.80 & 2.87 & & \\
\hline 43 & 530.50 & 11.70 & & \\
\hline & & & & \\
\hline
\end{tabular}

Figure 5: Roof stratum for the 4203 panel (not to scale).

the main bed separation in the middle part continue to expand. The main bed separation in the middle part is closed when the LTCC face advances $255 \mathrm{~m}$. At this point, most part of the lower bed separation is closed while the upper bed separation develops to its maximum $(2.93 \mathrm{~m})$, shown in Figure 8. With the advancing of the LTCC face, the upper bed separation begins to close, and it is totally closed when the LTCC face advances $335 \mathrm{~m}$. In this process, the lower bed separation continues to develop along the longwall face advancing, and a new bed separation is generated. The distribution characteristic of the bed separation is obtained through the CDEM simulation of the rapture and settlement of the overburden of the 4203 LTCC panel. It can be seen from Figure 7: the lower KS is an important bearing structure which controls the movement of the lower strata. The upper KS is an ultimate bearing structure controlling the movement of the upper strata and the surface subsidence.
3.3. BSBG Scheme. The BSBG technique could backfill the void space of the bed separation in the overburden through a surface borehole. After the grout set down and solidified, a compacted grouting bearing zone, which supports the overlaying strata and ensures the stability of the key stratum, is generated at the core area of the goaf. Therefore, the overlying key stratum (KS), stage coal pillar, and compacted grouting bearing zone could form a composite supporting and bearing structure to controlling the movement of the overlying strata and mitigate the surface subsidence.

3.3.1. The Borehole Depth of the BSBG. On the one hand, the target grouting zone is mainly the bed separation below the $\mathrm{KS}$ in the overburden. Hence, the borehole depth of the BSBG should be greater than the burial depth of the primary KS or target subordinate KS. On the other hand, the bottom of the borehole should be above the vertical water-conducting fracture zone. The CDEM simulation indicates the height of vertical water-conducting fracture is $47.0 \mathrm{~m}$. According to the empirical formula of $(4)[38,39]$, the height of the water-conducting fracture zone is $46.9 \pm 5.6 \mathrm{~m}$. The numerical simulation results are consistent with the empirical formula results. For safety consideration, take the greatest value of $52.5 \mathrm{~m}$ as the height of the water-conducting fracture zone for subsequent analysis. Furthermore, a safe distance, which is 3 times of the coal seam thickness (i.e. $3 \times 6.8=34.0 \mathrm{~m}$ ), is chosen to prevent the grout from flowing into the gob area through the water-conducting fractures. Hence, the bottom of the grouting borehole should be $86.5 \mathrm{~m}$ away from the roof of the 4 \# coal seam. Therefore, the target backfill grouting areas are the upper bed separation below the primary KS and the small bed separations generated between the upper and lower KS.

$$
H_{l i}=\frac{100 \sum M}{1.6 \sum M+3.6} \pm 5.6,
$$

where $M$ stands for the thickness of the extracted coal seam.

3.3.2. Volume of Void Space and the Grout Takes Estimation. Generally, the volume of the void space for the bed separation is presumed to be $30 \% \sim 50 \%$ of the mined-out coal volume, and the injection ratio is equal to the ratio of the volume of compacted injected fill to the extracted coal seam [40]. In order to estimate the grout takes, the ultimate injection ratio is proposed [40]:

$$
\alpha_{u}=\left(1-\frac{H_{g}}{W \tan \varphi}\right)\left[1-\frac{H_{c}\left(K_{r}-1\right)}{M}\right],
$$

where $H_{g}$ stands for the height of grouting area away from the roof of the coal seam, $M$ is the width of the longwall panel, $\varphi$ is the angle of full subsidence, $H_{c}$ is the height of the caving zone, $K_{r}$ is the residual bulking factor of the caved rocks, and $M$ stands for the thickness of the extracted coal seam.

The spatial distribution characteristics of bed separation have been obtained by the CDEM simulation. Hence, the volume of the void space can be gained by image processing. 


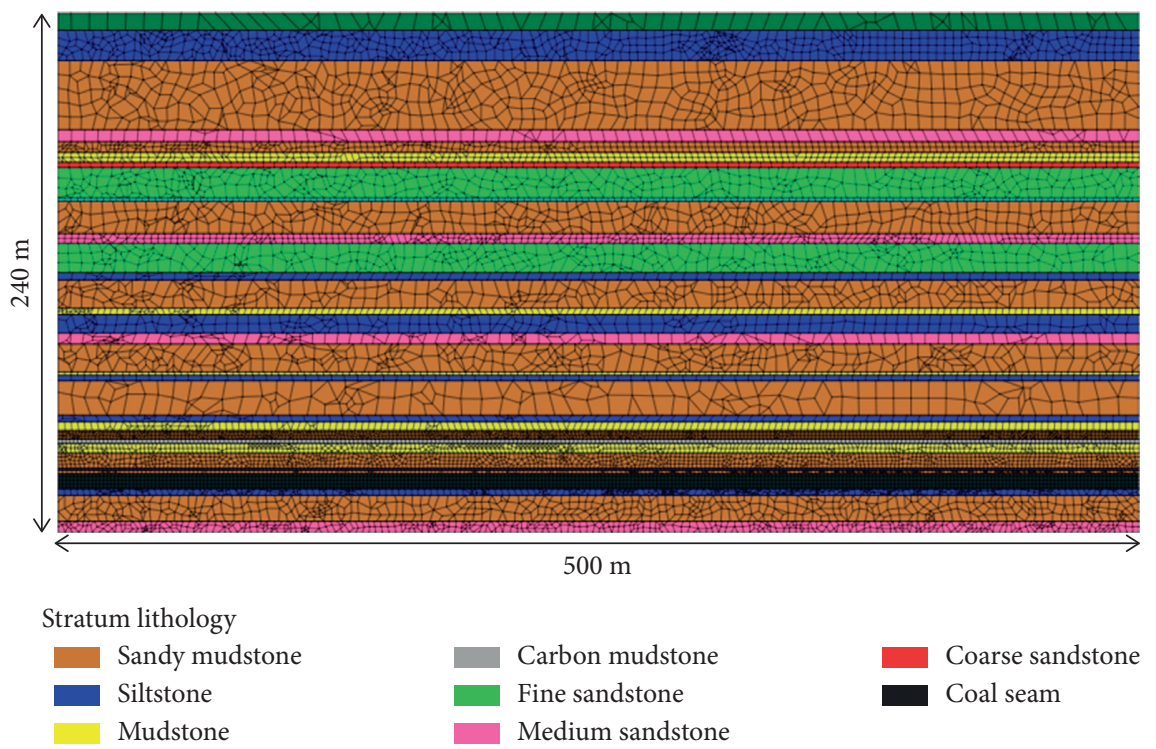

FIgURE 6: Numerical model of the 4203 LTCC panel.

TABle 1: Physical and mechanical properties of the strata.

\begin{tabular}{|c|c|c|c|c|c|c|c|}
\hline No. & Density $\left(\mathrm{kg} / \mathrm{m}^{3}\right)$ & $\begin{array}{c}\text { Elastic modulus } \\
(\mathrm{GPa})\end{array}$ & $\begin{array}{l}\text { Poisson's } \\
\text { ratio }\end{array}$ & $\begin{array}{c}\text { Tensile strength } \\
(\mathrm{MPa})\end{array}$ & $\begin{array}{l}\text { Cohesion } \\
(\mathrm{MPa})\end{array}$ & $\begin{array}{c}\text { Friction angle } \\
\left({ }^{\circ}\right)\end{array}$ & Lithology \\
\hline 1 & 2600 & 18.5 & 0.28 & 2.4 & 6.8 & 28.8 & Sandy mudstone \\
\hline 2 & 2480 & 22.0 & 0.27 & 4.5 & 8.6 & 17.4 & Siltstone \\
\hline 3 & 1370 & 1.65 & 0.32 & 1.2 & 1.9 & 28.2 & Coal seam \\
\hline 4 & 2460 & 8.75 & 0.28 & 0.6 & 1.4 & 30.0 & Mudstone \\
\hline 5 & 2530 & 16.5 & 0.30 & 2.2 & 4.2 & 18.5 & $\begin{array}{l}\text { Carbon } \\
\text { mudstone }\end{array}$ \\
\hline 6 & 2580 & 36.0 & 0.25 & 3.9 & 8.2 & 28.0 & Fine sandstone \\
\hline 7 & 2550 & 25.7 & 0.28 & 2.6 & 7.2 & 27.6 & $\begin{array}{l}\text { Medium } \\
\text { sandstone }\end{array}$ \\
\hline 8 & 2530 & 23.2 & 0.22 & 1.9 & 4.8 & 20.5 & Coarse sandstone \\
\hline
\end{tabular}

ImageJ, an open sources code, is utilized to account the ratio of the void space in the target bed separation zone. Firstly, the image of bed separation distribution is converted to gray scale, shown in Figure 9. The pixels of the bed separation are obtained automatically by setting the appropriate threshold. The average void ratio can be calculated through the pixels of the bed separation divided by all the pixels of the image. For the 4203 LTCC panel, the maximum void ratio of the target bed separation zone is $0.97 \%$ when the longwall face advances $255 \mathrm{~m}$. The grout takes can be predicted by

$$
Q=\frac{\eta \beta V}{m}
$$

where $\eta$ stands for the maximum void ratio, $\beta$ is the backfill rate, $V$ is volume of the target bed separation zone for BSBG, and $m$ is the consolidation ratio of the grout.

3.3.3. Grouting Pressure of the BSBG. Grouting pressure is the driving force for penetration and diffusion of the grout. For actual BSBG implementation, the grouting pressure should be higher than the gravity stress of the overburden on the one hand. However, the grouting pressure is not the greater and the better. The extremely high grouting pressure, at which the hydraulic fracture is generated, should be avoided. In practice, the grouting pressure is controlled by setting the surface grouting pressure

$$
p_{g}=p_{s}+H_{g} \gamma_{g} \geq \sum H_{i} \gamma_{i}
$$

where $p_{g}$ stands for the pressure in the underground grouting site, $p_{s}$ is the surface grouting pressure, $H_{g}$ is depth of the grouting site, $\gamma_{g}$ is the volumetric weight of the grout, $H_{i}$ is thickness of the $i$ th stratum, and $\gamma_{i}$ is the volumetric weight of the $i$ th stratum.

\section{BSBG Implementation and Discussion}

\subsection{Implementation of the BSBG}

4.1.1. Grouting Material and Grouting System. The coal gangue powder is the main grouting material in BSBG for Longquan coal mine. Injecting gangue powder into the bed separation zone can not only mitigate the ground subsidence but also solve the problems of environmental pollution and land occupation caused by traditional gangue stacking. The raw coal gangue was crushed and ground into powder and 


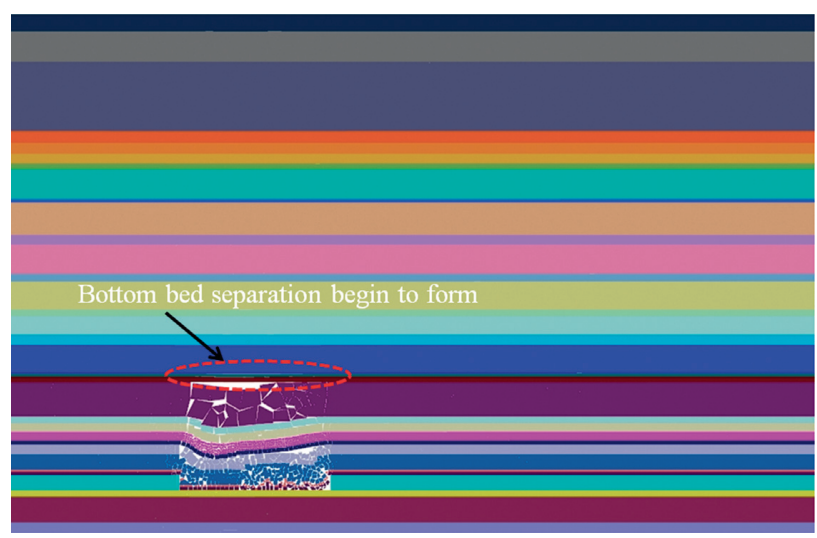

(a)

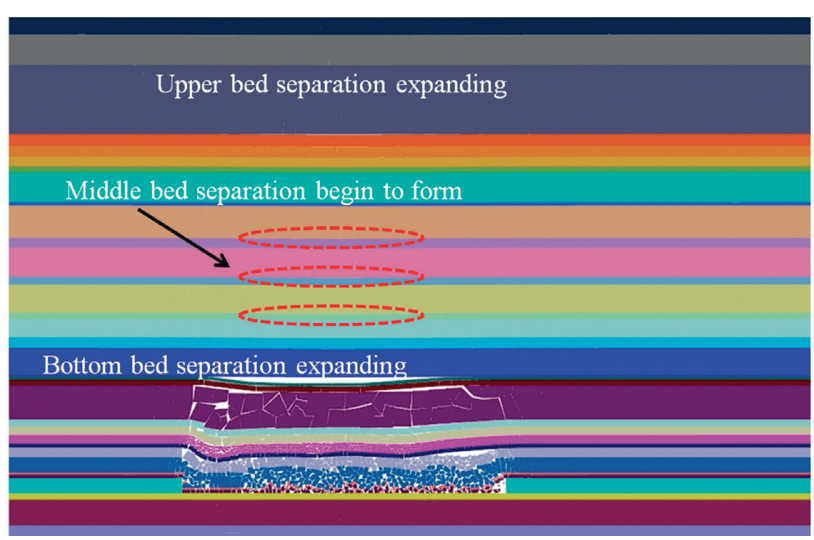

(c)

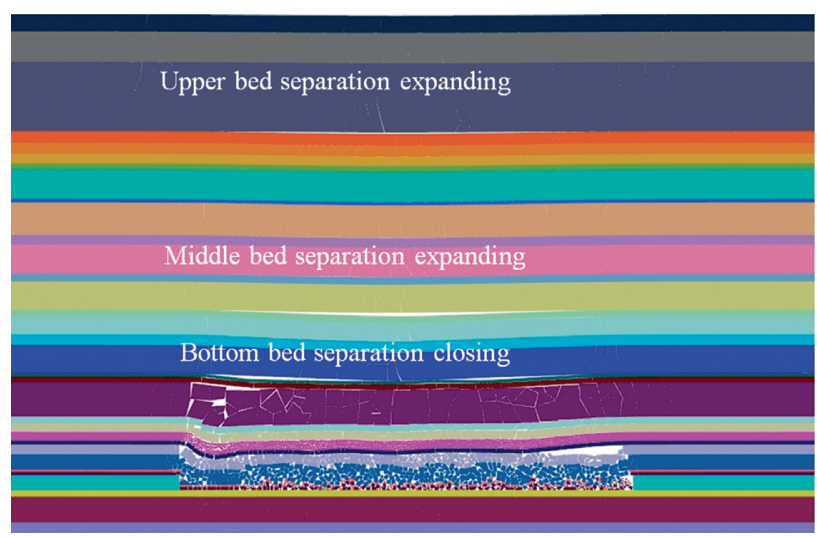

(e)

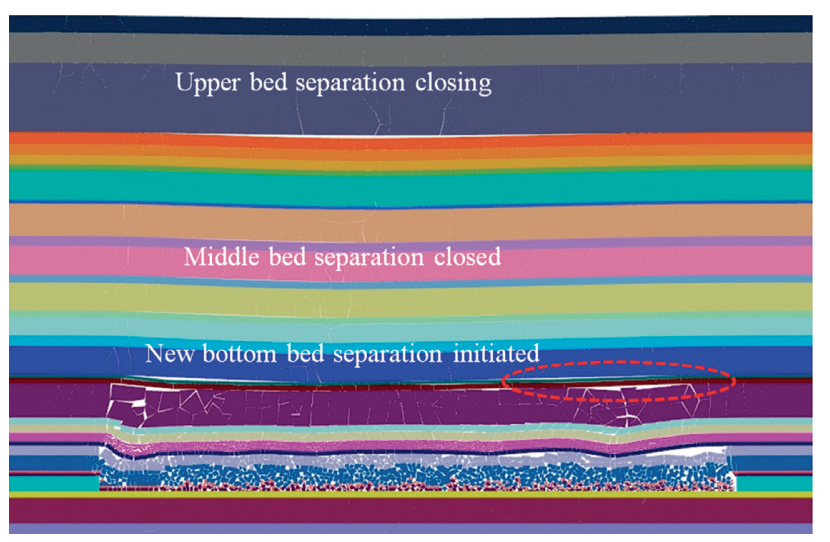

(g)

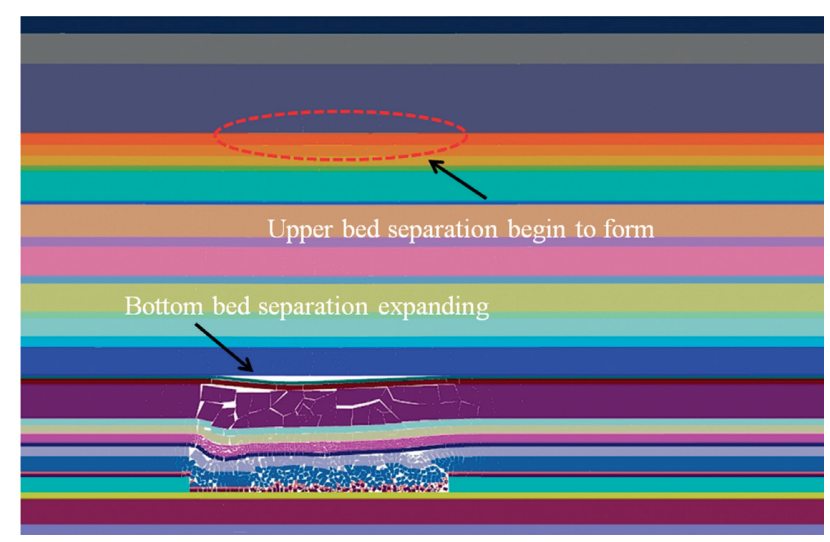

(b)

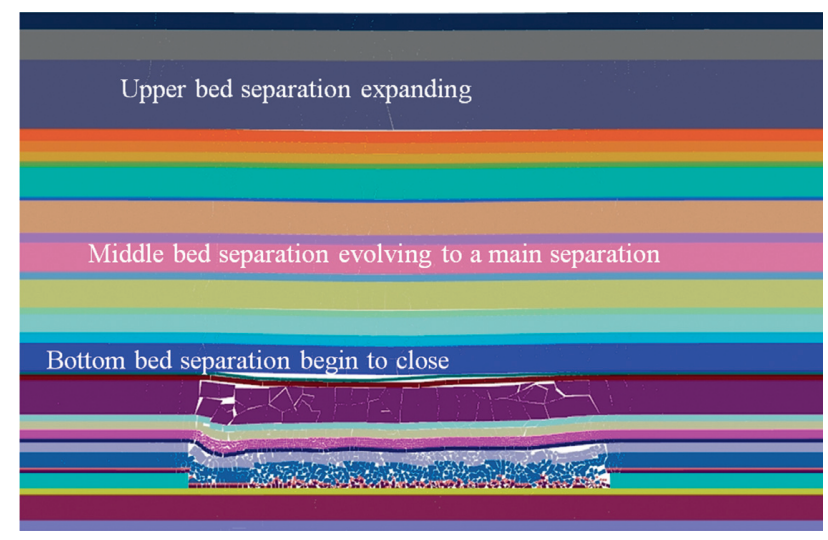

(d)

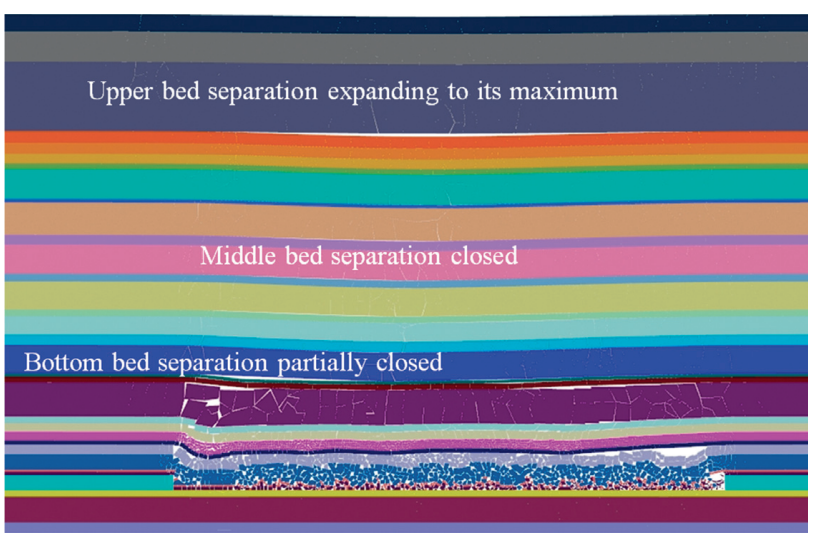

(f)

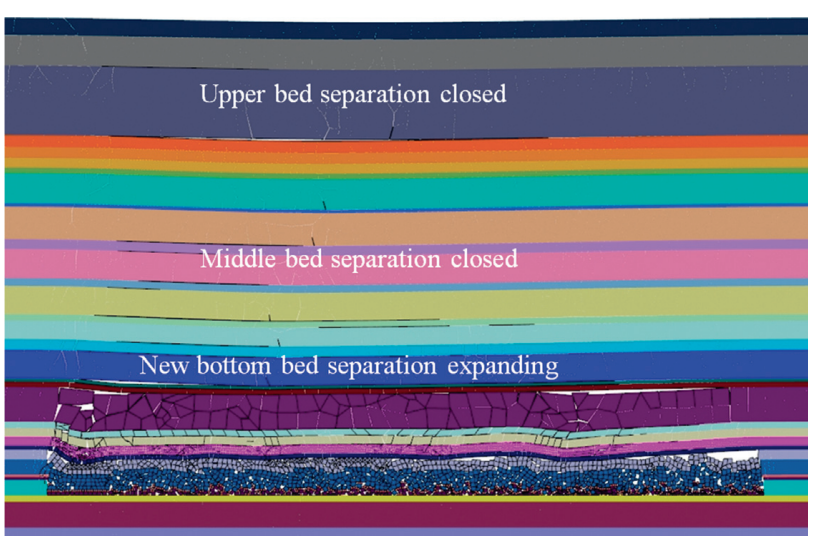

(h)

FIgURE 7: Evolution of bed separation in the overburden of the 4203 LTCC panel. The longwall face advancing (a) $70 \mathrm{~m}$, (b) $120 \mathrm{~m}$, (c) $150 \mathrm{~m}$, (d) $190 \mathrm{~m}$, (e) $210 \mathrm{~m}$, (f) $255 \mathrm{~m}$, (g) $295 \mathrm{~m}$, and (h) $335 \mathrm{~m}$. 


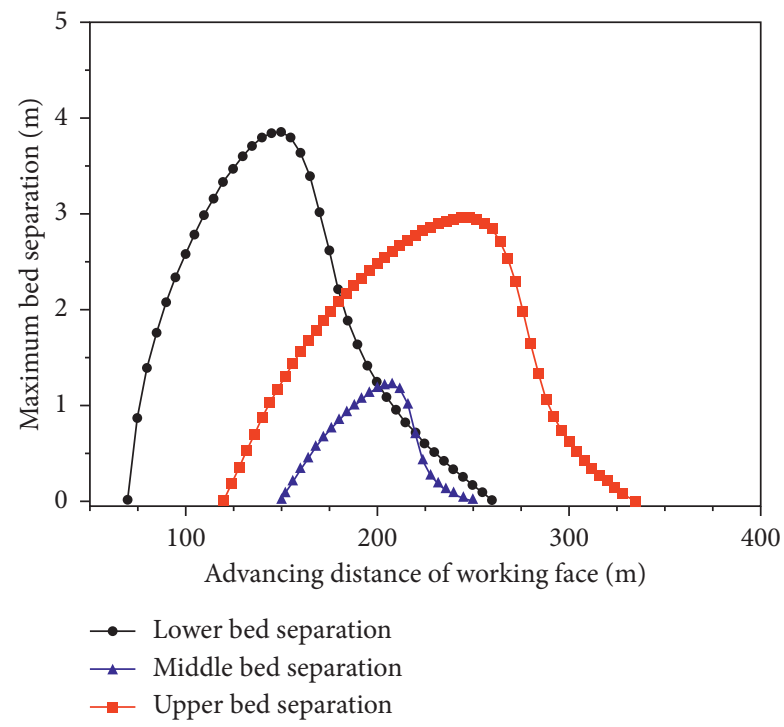

Figure 8: Maximum opening of bed separation versus the advancing distance of working face.
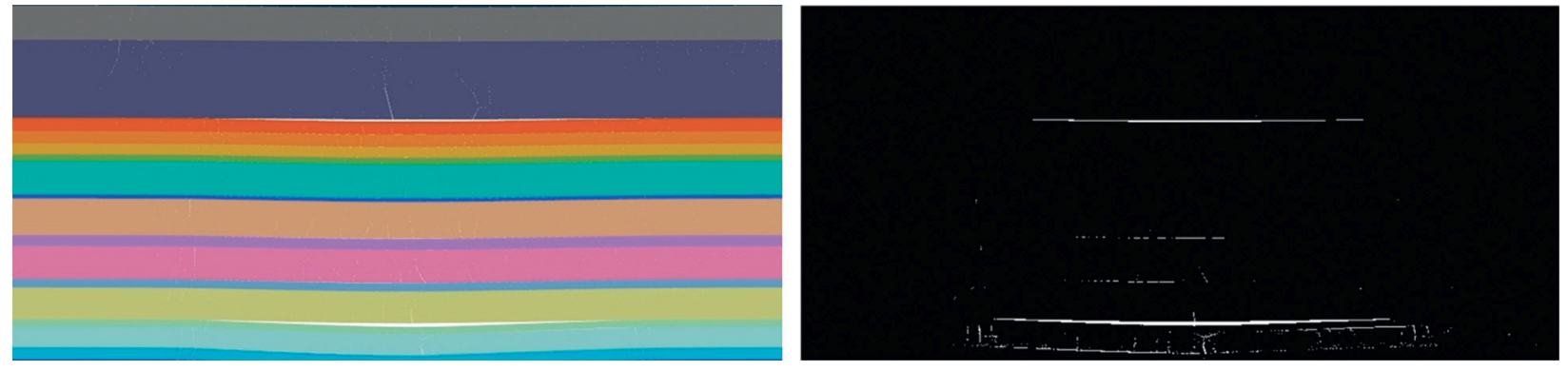

(a)
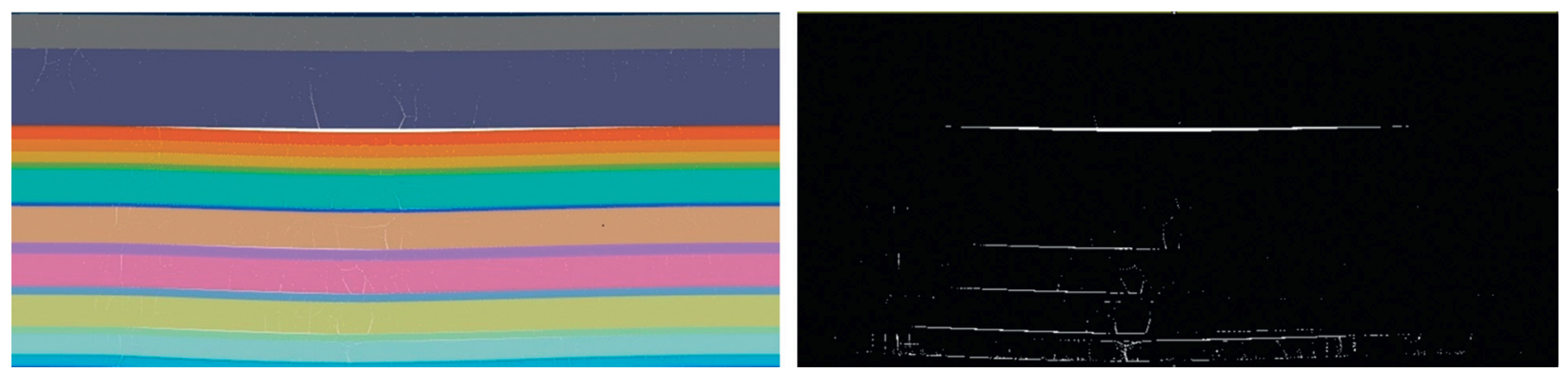

(b)

Figure 9: The converted binary image of the bed separation zone. (a) Longwall face advancing $210 \mathrm{~m}$. (b) Longwall face advancing $255 \mathrm{~m}$.

transported to the storage tank at the surface grouting station. The schematic diagram of the grouting system is illustrated in Figure 10. The gangue powder slurry is produced by mixing the gangue powder with water with the pulping machine, and some suspending agent was added during the mixing process. The pulping capacity is 2000 cubic meters per day. In the secondary mixing tank, some accelerating additives were added into the slurry. Finally, the gangue powder slurry was injected into the grouting borehole by the grouting pump through slurry pipeline.
4.1.2. Grouting Borehole Arrangement. The number and location of the grouting boreholes in BSBG are closely related to the diffusion radius of the slurry and the size of the longwall panel. In order to achieve a better subsidence mitigation effect, it should inject as much slurry into the overburden as possible. Generally, the more grouting boreholes, the better grouting effect can be achieved. However, the more boreholes, the higher costs will be. As the maximum bed separation below the key stratum (KS) occurred in the core part of the goaf, the grouting boreholes are generally arranged in the middle of the panel along the strike 


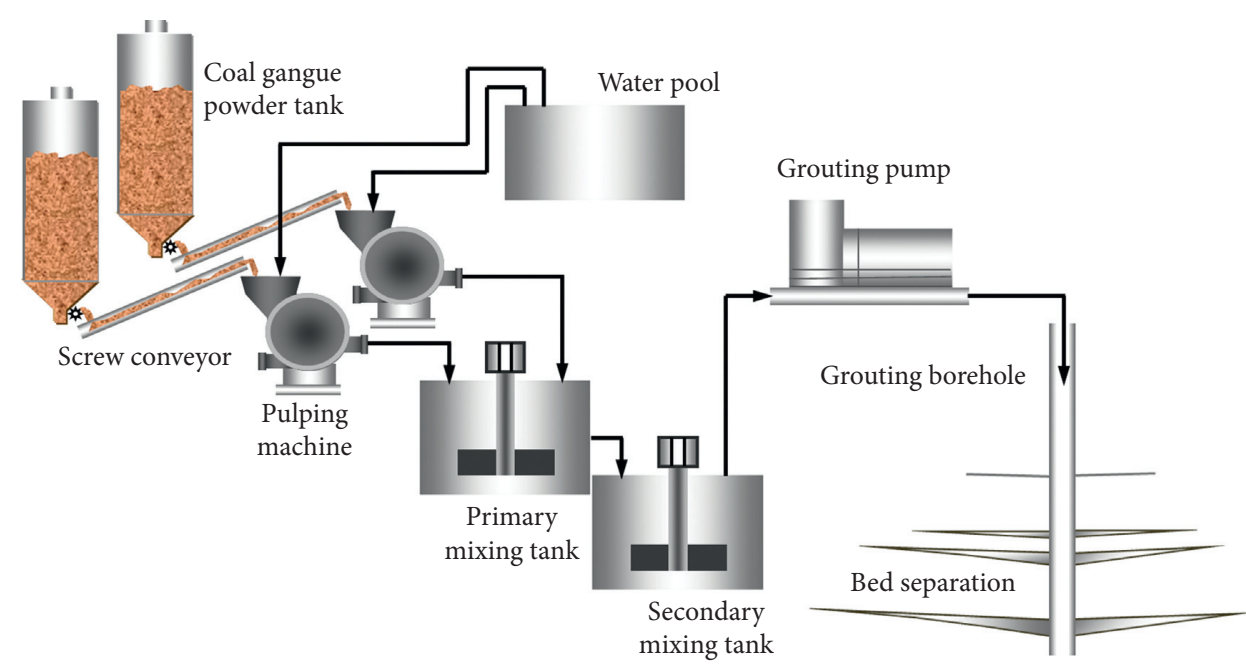

FIGURE 10: Schematic diagram of the grouting system.

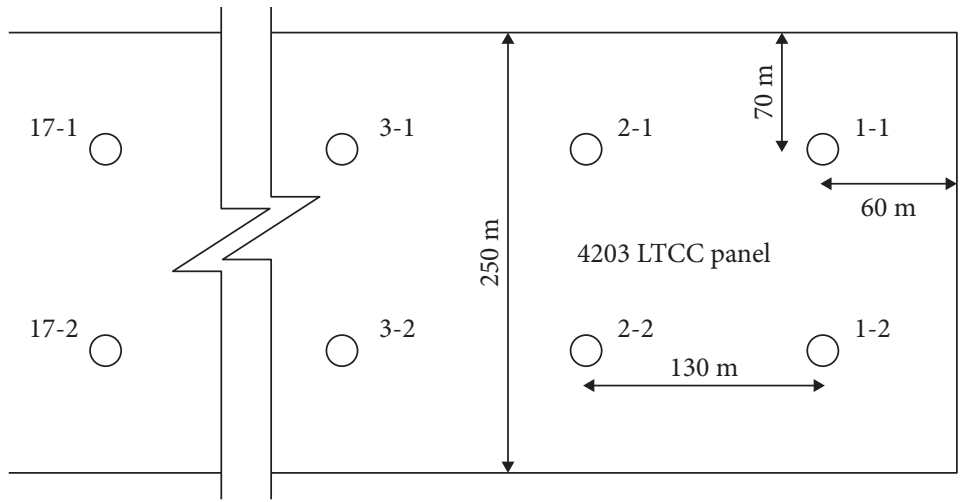

(a)

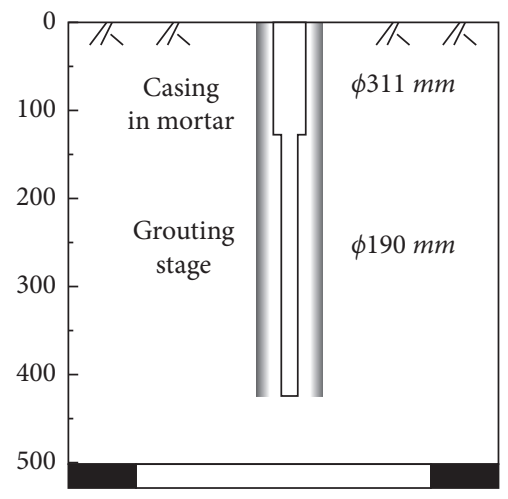

(b)

FIGURE 11: Grouting borehole arrangement and borehole structure. (a) Grouting borehole arrangement. (b) Borehole structure.

direction. In this way, the compacted grouting filling body can support the overlying strata in time to prevent the failure and caving of the KS. The borehole arrangement of BSBG in the 4203 panel is illustrated in Figure 11(a); there are two rows of boreholes, with spacing $130 \mathrm{~m}$, arranged along the strike direction. And the row spacing is $110 \mathrm{~m}$. The grouting borehole structure is shown in Figure 11(b), the diameter of the borehole is $\phi 311 \mathrm{~mm}$ in the casing section, and the casing diameter is $\phi 219 \mathrm{~mm}$. In the grouting section, the borehole diameter is $\phi 190 \mathrm{~mm}$, and a slotted pipe with diameter $\phi 168 \mathrm{~mm}$ is installed as the grouting channel.

\subsection{Results and Discussion}

4.2.1. Grouting Time Controlling. The lower bed separation is initiated at the earliest time, and it is close to the water-conducting fracture zone. In order to avoid the backfill grout flow into the longwall face, the lower bed separation is not grouted. The CDEM simulation indicates that the upper bed separation generated earlier than the middle bed separation, and the upper bed separation keeps expanding as the middle bed separation evolves from initiation to closure. Hence, it a good choice to start the BSBG at the time when the upper bed separation is generating. According to the simulation results, the upper bed separation begins to separate when the working face advances $120 \mathrm{~m}$. Therefore, the first grouting of BSBG is implemented when the borehole lags behind the longwall face $120 \mathrm{~m}$.

4.2.2. Surface Subsidence Mitigation. As the void space ratio of the bed separation zone is obtained through the image processing, when the advancing distance of longwall face equals to the width of the face, that is, $250 \mathrm{~m}$, the predicated grout takes is $7.2 \times 10^{4} \mathrm{~m}^{3}$ using Equation (6). And the actual grout takes is $7.362 \times 10^{4} \mathrm{~m}^{3}$. The grout takes prediction with image processing method is slightly smaller than the actual grout takes. It is worth noting that the pixels of a few vertical cracks are also counted into the pixels of the bed separation. However, in the actual grouting process, those vertical cracks could also be filled with grout if it is connected with the bed separation. After the BSBG implementation, a checking borehole, with borehole depth of $380.0 \mathrm{~m}$, was drilled to verify the backfill grouting effectiveness. There was no sudden free fall or accelerated sinking of the drill tool and the fluid loss was not significant in the drilling process. In 


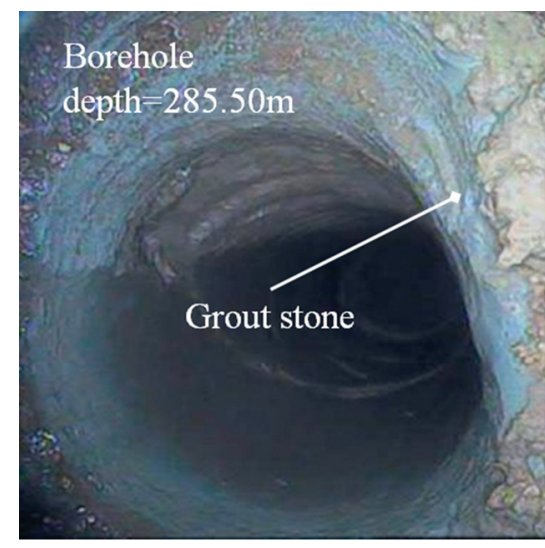

(a)

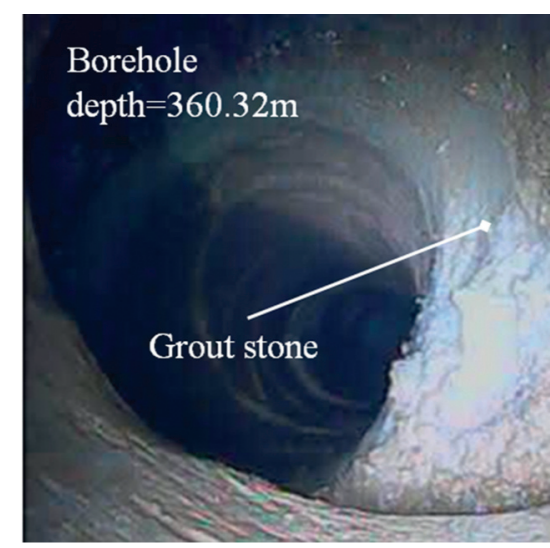

(b)

Figure 12: Grout stone in the checking borehole.

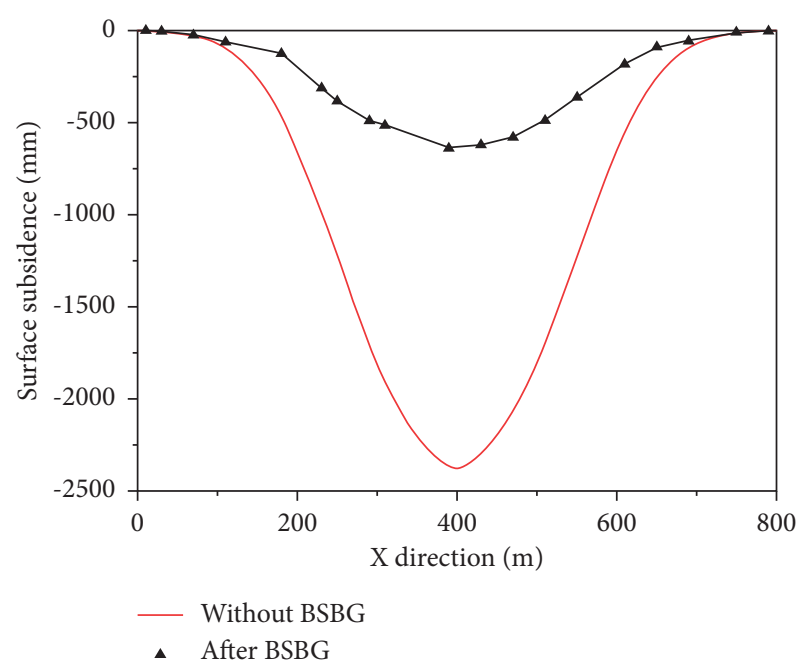

FIgURE 13: Surface subsidence measurements after the BSBG implementation.

addition, the borehole TV was used to observe the compactness of the backfill grouting. As shown in Figure 12, it can be clearly seen that the checking borehole encountered several layers of grout stone body, and the grout stone body has a good roof connection effect, which ensures a great supporting effect for the overburden.

In order to evaluate the effectiveness of the BSBG, the surface subsidence was monitored above the 4203 LTCC panel. And a total of 30 surface settlement observations were conducted. Figure 13 shows the actual monitored subsidence curve and predicted subsidence curve of the surface above the working face. Without BSBG, the predicted maximum surface subsidence of 4203 LTCC panel is $2369.4 \mathrm{~mm}$. By comparison, the practical maximum surface subsidence was measured to be $638.2 \mathrm{~mm}$ after the BSBG implementation, and the subsidence reduction ratio is $73.1 \%$. In the protected area, the maximum surface subsidence is $9.6 \mathrm{~mm}$, and there is no sudden settlement or uneven settlement generated, and no damage has occurred to the buildings. Up to now, the settlement rate is less than $0.1 \mathrm{~mm} / \mathrm{d}$, and the ground subsidence tends to be stable.

\section{Conclusions}

In order to provide reference for the BSBG design, the CDEM code was utilized to simulate the bed separation formation in the overburden of 4302 LTCC panel. The spatial distribution characteristics of bed separation and the relationship of dynamic evolution process of bed separation versus the advancing distance of the longwall face were obtained. The following conclusions were obtained, which can provide reference for surface subsidence mitigation in LTCC mining with similar conditions.

(1) The spatial distribution of bed separation and its dynamic evolution process are closely related to the lithological characters of overlying strata and the advancing distance of the longwall face. The bed separation in overburden of 4203 LTCC panel could be classified into three classes: the upper bed separation, the middle bed separation, and the lower bed separation.

(2) The upper bed separation had the longest duration time while the duration time of middle bed separation was the shortest. The lower bed separation was developed rapidly with the advance of the longwall face, and new bed separation was generated quickly after its closure. The main backfilling zone is the bed separation zone between the primary key stratum and subordinate key stratum for BSBG in the 4203 LTCC panel, and the BSBG should be initiated when longwall face advances ahead the borehole $120 \mathrm{~m}$.

(3) After the BSBG implementation, the surface subsidence was reduced by $73.1 \%$ compared with the predicted subsidence when no backfill grouting was implemented, and no sudden settlement or uneven settlement was occurred on the ground. Using the coal gauge powder as grouting materials, the BSBG could solve the problems of environmental pollution and land occupation caused by traditional gangue stacking. 


\section{Data Availability}

The data used to support the findings of this study are available from the corresponding author upon request.

\section{Ethical Approval}

This article does not contain any studies with human participants or animals performed by any of the authors.

\section{Conflicts of Interest}

The authors declare that they have no conflicts of interest.

\section{Acknowledgments}

This work has been supported by the National Key Research and Development Program of China (grant no. 2018YFC 0604501).

\section{References}

[1] E. Can, Ş. Kuşcu, and M. E. Kartal, "Effects of mining subsidence on masonry buildings in Zonguldak hard coal region in Turkey," Environmental Earth Sciences, vol. 66, no. 8, pp. 2503-2518, 2012.

[2] D. Xuan and J. Xu, "Grout injection into bed separation to control surface subsidence during longwall mining under villages: Case study of Liudian coal mine, China," Natural Hazards, vol. 73, no. 2, pp. 883-906, 2014.

[3] D. Xuan and J. Xu, "Longwall surface subsidence control by technology of isolated overburden grout injection," International Journal of Mining Science and Technology, vol. 27, no. 5, pp. 813-818, 2017.

[4] S. G. Chen and H. Guo, "Numerical simulation of bed separation development and grout injecting into separations," Geotechnical \& Geological Engineering, vol. 26, no. 4, pp. 375-385, 2008.

[5] H. Teng, J. Xu, D. Xuan, and B. Wang, "Surface subsidence characteristics of grout injection into overburden: Case study of Yuandian No. 2 coalmine, China," Environmental Earth Sciences, vol. 75, no. 6, p. 530, 2016.

[6] Y. Yang, Y. Xu, S. Shen, and Y. Yuan, "Mining-induced geohazards with environmental protection measures in Yunnan, China: An overview," Bulletin of Engineering Geology and the Environment, vol. 74, no. 1, pp. 141-150, 2015.

[7] E. Can, Ç. Mekik, Ş. Kuşcu, and H. Akçın, "Monitoring deformations on engineering structures in kozlu hard coal basin," Natural Hazards, vol. 65, no. 3, pp. 2311-2330, 2013.

[8] W. Liu, J. Xu, W. Zhu, and S. Wang, "A novel short-wall caving zone backfilling technique for controlling mining subsidence," Energy Science \& Engineering, vol. 7, no. 5, pp. 2124-2137, 2019.

[9] S. Chen, D. Yin, F. Cao, Y. Liu, and K. Ren, "An overview of integrated surface subsidence-reducing technology in mining areas of China," Natural Hazards, vol. 81, no. 2, pp. 1129-1145, 2016.

[10] W. Guo, H. Wang, and S. Chen, "Coal pillar safety and surface deformation characteristics of wide strip pillar mining in deep mine," Arabian Journal of Geosciences, vol. 9, no. 2, p. 137, 2016.

[11] J. Zhang, Q. Zhang, Q. Sun, R. Guo, D. Germain, and S. Abro, "Surface subsidence control theory and application to backfill coal mining technology," Environmental Earth Sciences, vol. 74, no. 2, pp. 1439-1448, 2015.

[12] W. Sun, Q. Zhang, Y. Luan, and X.-P. Zhang, "A study of surface subsidence and coal pillar safety for strip mining in a deep mine," Environmental Earth Sciences, vol. 77, no. 17, p. 627, 2018.

[13] E. Bai, W. Guo, Y. Tan, and D. Yang, "The analysis and application of granular backfill material to reduce surface subsidence in China's northwest coal mining area," PLOS ONE, vol. 13, Article ID e201112, 2018.

[14] T. Liu, "Mining response on rock masses and control engineering and their application," Science and Technology Review, vol. 12, no. 12, pp. 21-23, 1994.

[15] V. Palchik, "Experimental investigation of apertures of mining-induced horizontal fractures," International Journal of Rock Mechanics and Mining Sciences, vol. 47, no. 3, pp. 502-508, 2010.

[16] V. Palchik, "Formation of fractured zones in overburden due to longwall mining," Environmental Geology, vol. 44, no. 1, pp. 28-38, 2003.

[17] Y. Gao, "Four-Zone model of rockmass movement and back analysis of dynamic displacement," Journal of China Coal Society, vol. 01, pp. 51-56, 1996.

[18] Y. Zhang and L. Chen, "Conditions for bed separation of overlying burden in longwall mining," Journal of China Coal Society, vol. 21, no. 6, pp. 576-581, 1996.

[19] J. Zhang, G. Liao, Z. Huang, E. Feng, and Q. Liu, “Dynamic priciples of development of strata (bed) separation by fully mechanized top coal caving," Journal of University of Science and Technology Beijing, vol. 23, no. 06, pp. 492-494, 2001.

[20] Y. Gao, X. Niu, and J. Liao, "Analysis on grouting pressure when grouting in overburden bed-separations in mine," Chinese Journal of Rock Mechanics and Engineering, vol. 23, no. S2, pp. 5244-5247, 2004.

[21] Z. Wang, X. Guo, Y. Gao, and C. Chen, "Study of grouting technology of overburden-separation to reduce ground subsidence in Huafeng coal mine," Chinese Journal of Rock Mechanics and Engineering, vol. 33, no. S1, pp. 3249-3255, 2014.

[22] C. Liu, H. Li, H. Mitri, and D. Jiang, "Strata movement and shield pressure analysis at Tongxin longwall top coal caving working face with extra-thick coal seam," Arabian Journal of Geosciences, vol. 12, no. 24, p. 786, 2019.

[23] B. Wang, J. Xu, and D. Xuan, "Time function model of dynamic surface subsidence assessment of grout-injected overburden of a coal mine," International Journal of Rock Mechanics and Mining Sciences, vol. 104, pp. 1-8, 2018.

[24] V. Palchik, "Localization of mining-induced horizontal fractures along rock layer interfaces in overburden: field measurements and prediction," Environmental Geology, vol. 48, no. 1, pp. 68-80, 2005.

[25] N. Xu and Y. Zhang, "Application of the bed separation grouting in surface subsidence controlling," Coal Science and Technology, vol. 28, no. 9, pp. 1-3, 2000.

[26] M. Qian, "On sustainable coal mining in China," Journal of Coal Society, vol. 35, no. 04, pp. 529-534, 2010.

[27] J. Xu and M. Qian, "Study and application of mining-induced fracture distribution in Green Mining," Journal of China University of Mining \& Technology, vol. 33, no. 2, pp. 17-20, 2004.

[28] J. Xu, M. Qian, and W. Zhu, "Study on influences of primary key stratum on surface dynamics subsidence," Chinese Journal of Rock Mechanics and Engineering, vol. 24, no. 5, pp. 787-791, 2005. 
[29] C. Joulin, J. Xiang, and J. Latham, "A novel thermo-mechanical coupling approach for thermal fracturing of rocks in the three-dimensional FDEM," Computational Particle Mechanics, vol. 7, no. 5, pp. 935-946, 2020.

[30] A. Munjiza, The Combined Finite-Discrete Element Method, John Wiley \& Sons, England, 2004.

[31] C. Feng, S. Li, and X. Liu, "A semi-spring and semi-edge combined contact model in CDEM and its application to analysis of Jiweishan landslide," Journal of Rock Mechanics and Geotechnical Engineering, vol. 6, no. 1, pp. 26-35, 2013.

[32] S. Li, M. Zhao, Y. Wang, and Y. Rao, "A new numerical method for dem $\dot{i}$ block and particle model," International Journal of Rock Mechanics and Mining Sciences, vol. 41, no. 3, p. 436, 2004.

[33] X. Zhu, C. Feng, P. Cheng, X. Wang, and S. Li, "A novel three-dimensional hydraulic fracturing model based on continuum-discontinuum element method," Computer Methods in Applied Mechanics and Engineering, vol. 383, Article ID 113887, 2021.

[34] T. Lukas, G. G. Schiava D’Albano, and A. Munjiza, "Space decomposition based parallelization solutions for the combined finite-discrete element method in 2D," Journal of Rock Mechanics and Geotechnical Engineering, vol. 6, no. 6, pp. 607-615, 2014.

[35] M. Paterson and T. Wong, Experimental Rock Deformation-The Brittle Field, Springer, New York, 2005.

[36] Y. Ju, P. Liu, J. Chen, Y. Yang, and P. G. Ranjith, "CDEMbased analysis of the 3D initiation and propagation of hydrofracturing cracks in heterogeneous glutenites," Journal of Natural Gas Science and Engineering, vol. 35, pp. 614-623, 2016.

[37] Q. Zhang, J. Yue, C. Liu, C. Feng, and H. Li, "Study of automated top-coal caving in extra-thick coal seams using the continuum-discontinuum element method," International Journal of Rock Mechanics and Mining Sciences, vol. 122, p. 104033, 2019.

[38] F. Wan, H. Zhang, P. Zhou, and J. Guo, "Determination of water-proof coal (rock) pillar height in mining coal seam group under water-bearing rock stratum," Shock and Vibration, vol. 2021, Article ID 6699726, 2021.

[39] State Bureau Of Coal Industry, Regulations of Coal Pillar Design and Extraction for Biuldings, Water Bodies, Railways, Main Shafts and Roadways, Coal Industry Press, Beijing, China, 2000.

[40] D. Xuan, J. Xu, B. Wang, and H. Teng, "Investigation of fill distribution in post-injected longwall overburden with implications for grout take estimation," Engineering Geology, vol. 206, pp. 71-82, 2016. 